\title{
Effectiveness of Coriandrum sativum Extract as Antimicrobial by Applying on Six Bacterial Strains
}

\author{
Faroug Bakheit Mohamed Ahmed, Abd El-Mohymen Jaber Alla
}

Faculty of Science and Technology, Shendi University, Shendi, Sudan

\section{Email address:}

farougmhmd@gmail.com (F. B. M. Ahmed)

\section{To cite this article:}

Faroug Bakheit Mohamed Ahmed, Abd El-Mohymen Jaber Alla. Effectiveness of Coriandrum sativum Extract as Antimicrobial by Applying on Six Bacterial Strains. Journal of Diseases and Medicinal Plants. Vol. 5, No. 6, 2019, pp. 103-106. doi: 10.11648/j.jdmp.20190506.13

Received: September 23, 2019; Accepted: November 27, 2019; Published: December 7, 2019

\begin{abstract}
The study aimed to detect the antibacterial activity of coriander extract via investigation of six types of bacteria; three gram-positive reference strain were (Bacillus cereus ATCC 11778, Staphylococcus aureus ATCC 25923 and Enterococcus faecalis ATCC 29212), whilst three gram-negative reference strains were (Escherichia coli ATCC 25922, Salmonella typhimurium ATCC 13311 and Pseudomonas aeruginosa ATCC 27853). All bacterial strains were stored in Brain Heart Infusion (BHI) broth with $20 \%(\mathrm{v} / \mathrm{v})$ glycerol at $280^{\circ} \mathrm{C}$. Prior to susceptibility testing, each strain was inoculated on BHI agar to ensure optimal growth and purity plating suitable. Four different concentrations $(12.5 \%, 25 \%, 50 \%$ and $100 \%)$ of the oil were dissolved in dimethyl sulfoxide (DMSO) in triplicates using nutrient agar medium. In general, our study revealed that the coriander oil appeared higher influence on the positive gram strain rather than negative gram strain; this might be due to the gram positive strains are more sensitive and potential of hydrophobic essential oils to disrupt the bacterial cell membrane. The results showed that all tested concentrations of coriander oil as antibacterial activity against gram positive and gram negative bacteria; Salmonella typhimurium and Enterococcus fecalis respectively were appeared resistance at the concentrations $12.5 \%$. In addition the concentration 100\% inflicted the highest antibacterial activities. The most susceptible bacteria strains was Staphylococcus aureus with highest inhibition zone values $(33 \mathrm{~mm})$ at concentration $25 \%$ and $100 \%(40 \mathrm{~mm})$.
\end{abstract}

Keywords: Coriander, Extract, Antibacterial, Strain and DMSO

\section{Introduction}

Coriandrum sativum (coriander) probably originated from Eastern Mediterranean and it was spread as a spice plant to India, China, Russia, Central Europe, and Morocco, and has been cultivated since human antiquity [1]. Coriander seeds are often sown in autumn but may also be sown in the spring. When growing coriander from seeds, sown the coriander seeds in rows about 15 inches apart spaced 1 inch asunder and one-half inch deep. Many herb gardeners grow coriander primarily for cilantro leaves and only leave a plant or two to produce seeds [2].

The chemical constituents of coriander leaves and seeds are; protein 21.93 and $12.37 \mathrm{~g}$, total lipid (fat) 4.78 and $17.77 \mathrm{~g}$, carbohydrate 52.10 and $54.99 \mathrm{~g}$, fiber 10.40 and $41.9 \mathrm{~g}$, calcium 1246 and $709 \mathrm{mg}$, iron 42.46 and $16.32 \mathrm{mg}$, phosphorus 481 and $409 \mathrm{mg}$, magnesium 694 and $330 \mathrm{mg}$, potassium 4466 and $1267 \mathrm{mg}$, sodium 211 and $35 \mathrm{mg}$, zinc 4.72 and $4.70 \mathrm{mg}$, vitamin C 566.7 and $21 \mathrm{mg}$, thiamin 1.252 and $0.239 \mathrm{mg}$, riboflavin 1.500 and $0.290 \mathrm{mg}$, niacin 10.707 and $2.130 \mathrm{mg}$, vitamin B-120.00 and $0.00 \mu \mathrm{g}$, vitamin A, RAE 293 and $0.00 \mu \mathrm{g}$, vitamin D (D2 + D3) 0.00 and $0.00 \mu \mathrm{g}$, respectively. Coriander leaves contain high levels of organic compounds called aldehydes. The same aldehydes, or similar, are often commonly found in soaps and lotions. Studies have also suggested that crushing coriander leaves may lead to faster breakdown of aldehydes, diminishing the soapy taste [3].

The use of coriander dated back to around $1550 \mathrm{BC}$, and it was one of the oldest spice crops in the world. Medicinally, it was used as stimulant, aromatic and carminative. The powdered fruit, fluid extract and oil are chiefly used medicinally as flavouring to disguise the taste of active purgatives and correct their griping tendencies. However, seeds were applied locally to alleviate swelling and pains. Paste of green coriander was used for headache. Externally, powdered green coriander was used to alleviate burning sensation and pain in diseases like inflammation caused by erysipelas and lymphadenopathy. Decoction of green 
coriander was used in stomatitis. Nasal drops of green coriander act as a haemostat and thus stop bleeding in epistaxis. Juice or decoction of green coriander was used in conjunctivitis [4]. The leaves are used as a tonic, for urinary infection as a carminative, stimulant and pectoral, for leucoderma and skin disease [5]. The seeds were included in many prescriptions as carminative and for the treatment of fever, diarrhoea, vomiting and indigestion [6]. The fruit (seed) is used in menstrual disorders as an aphrodisiac [7].

Oils contained within plant cells are liberated through heat and pressure from various parts of the plant matter; for example, the leaves, flowers, fruit, grass, roots, wood, bark, gums and blossom. The extraction of essential oils from plant material can be achieved by various methods, of which hydro-distillation, steam and steam/water distillation are the most common method of extraction [8]. Other methods include solvent extraction, aqueous infusion, cold or hot pressing, effleurage, supercritical fluid extraction and phytonic process. This later process has been newly developed; it uses refrigerant hydrofluorocarbons solvents at low temperatures (below room temperature), resulting in good quality of the extracted oils [9].

Because of the variability of amounts and profiles of the components of essential oils, it is likely that their antimicrobial activity is not due to a single mechanism, but to several sites of action at the cellular level. Then, different modes of action are involved in the antimicrobial activity of essential oils. One of the possibilities for action is the generation of irreversible damage to the membrane of bacterial cells, that induce material losses (cytoplasmic), leakage of ions, loss of energy substrate (glucose, ATP), leading directly to the lysis of bacteria (cytolysis) and therefore death [10]. Another possibility of action is inhibition of production of amylase and protease which stop the toxin production, electron flow and result in coagulation of the cell content [11]. Antifungal actions are quite similar to those described for bacteria. However, two additional phenomena inhibiting the action of yeast are worth mentioning; the establishment of a $\mathrm{pH}$ gradient across the cytoplasmic membrane and the blocking of energy production of yeasts which involve the disruption of the membrane. Different mechanisms of antiviral activity of different essential oils and their constituents seem to be present. The antiviral activity of the essential oil is principally due to direct virucidal effects (by denaturing viral structural proteins or glycoproteins). Proposed mechanisms suggest that essential oils interfere with the virus envelope by inhibiting specific processes in the viral replication cycle or by masking viral components, which are necessary for adsorption or entry into host cells, thus, they prevent the cellto-cell virus diffusion [12].

\section{Objective of the Study}

The present study acts to investigate the effect of Coriandrum sativum (coriander) extract as antibacterial agent.

\section{Method}

Coriander oil was extracted by steam distillation process via water and steam method. To evaluate the antibacterial activity of coriander oil, six types of bacteria (three grams positive and three gram negative) were selected. The agar plate method was adopted to evaluate the antibacterial activity of the extracted oil.

Procedure:

The medium was cool to $45-50^{\circ} \mathrm{C}$ placed in the plates, then allowed to adjust the surface level to a depth of about $4 \mathrm{~mm}$. Antibiotic drug stocks were kept at $-20^{\circ} \mathrm{C}$. Cotton wool swab supplies are prepared on wooden rod sticks. $2 \mathrm{ml}$ mixture of bacterial suspension was prepared thoroughly uniformed with $250 \mathrm{ml}$ nutrient agar at $45^{\circ} \mathrm{C}$. Agar inoculation $(20-25 \mathrm{ml})$ was distributed vouchers in sterile Petri dishes. Leaves were left to harden and 4 wells $(7 \mathrm{~mm}$ in diameter) were made using sterile cork bore. Grains (12.5, 25, 50 and 100\%) were prepared for oil extracted, as well as by dissolving the extracts and fractures in dimethyl sulfoxide (DMSO). The effects of coriander oil were investigated after 24-48 hours by measuring the diameter of the inhibition region of each treatment. Three replicates were performed for each extract / fracture and control of living organisms tested.

\section{Calculation:}

The relative percentage of test inhibition with respect to positive control using the following law:

Percentage of relative inhibition of test extraction $=\frac{(\mathrm{X}-\mathrm{Y}) \times 100}{(\mathrm{Z}-\mathrm{Y})}$

Where:

X: Total area of inhibition of the test extract.

Y: Total area of inhibition of the solvent.

$Z$ : Total area of inhibition of the standard drug.

\section{Result and Discussion}

The antibacterial activity of coriander oil was tested according to [13], with miner modification against six bacterial strains. The antibacterial activity included three gram-positive reference strain were (Bacillus cereus ATCC 11778, Staphylococcus aureus ATCC 25923 and Enterococcus faecalis ATCC 29212), whilst three gramnegativereference strains were (Escherichia coli ATCC 25922, Salmonella typhimurium ATCC 13311 and Pseudomonas aeruginosa ATCC 27853).

All bacterial strains were stored in Brain Heart Infusion (BHI) broth with $20 \%(\mathrm{v} / \mathrm{v})$ glycerol at $280^{\circ} \mathrm{C}$. Prior to susceptibility testing, each strain was inoculated on BHI agar to ensure optimal growth and purity plating suitable. Four different concentrations $(12.5 \%, 25 \%, 50 \%$ and $100 \%)$ of the oil were dissolved in dimethyl sulfoxide (DMSO) in triplicates using nutrient agar medium. The $\mathrm{pH}$ was adjusted to $\left(7.4\right.$ - 7.6) for bacteria. The plates were incubated at $37^{\circ} \mathrm{C}$ for 24 hour, and then the commercial antibiotic, gentamicin $(10 \mu \mathrm{g})$ was used as the positive control. The diameter of inhibition zones were measured, the obtained results were 
represented in Figures $(1,2,3,4,5$ and 6) and Table 1.

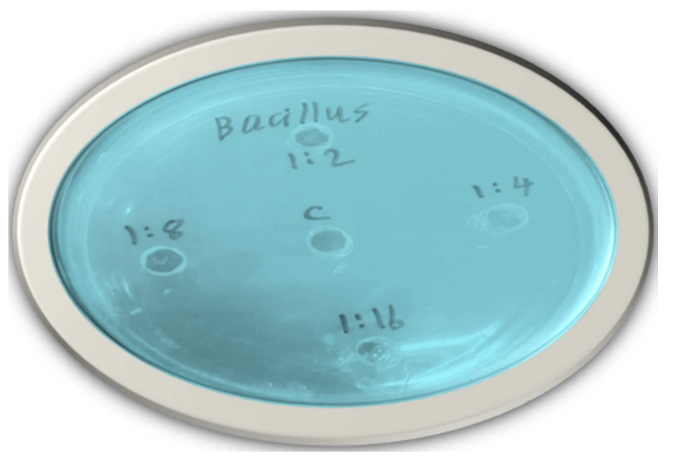

Figure 1. Effect of coriander oil on Bacillus cereus ATCC 11778.

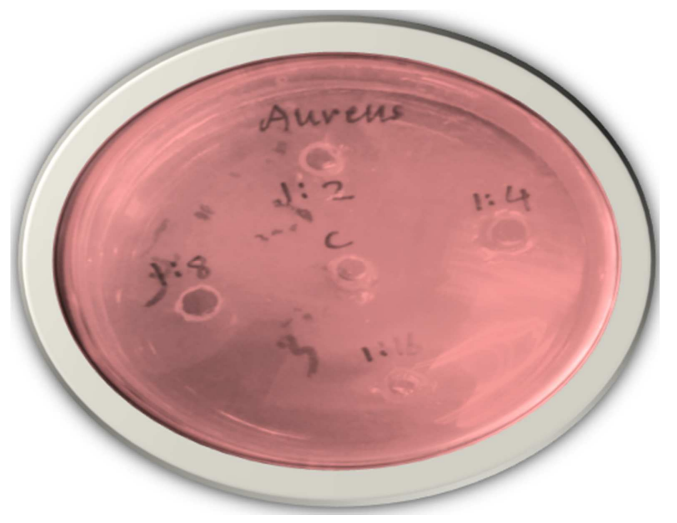

Figure 2. Effect of coriander oil on Staphylococcus aureus ATCC 25923.

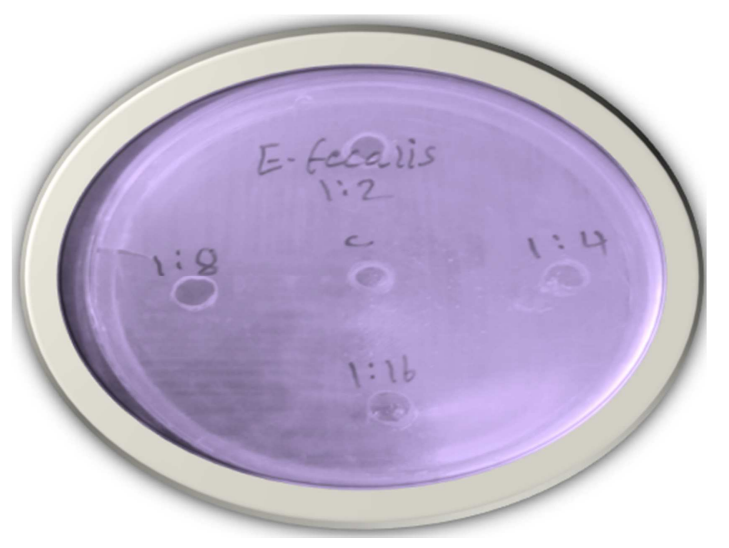

Figure 3. Effect of coriander oil on Enterococcus faecalis ATCC 29212.

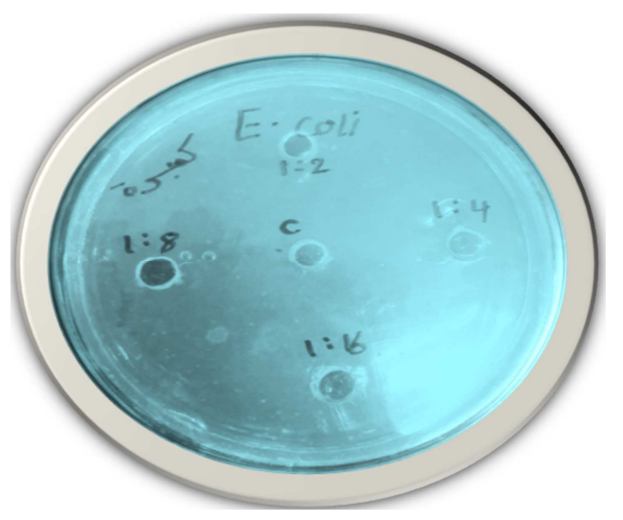

Figure 4. Effect of coriander oil on Escherichia coli ATCC 25922.

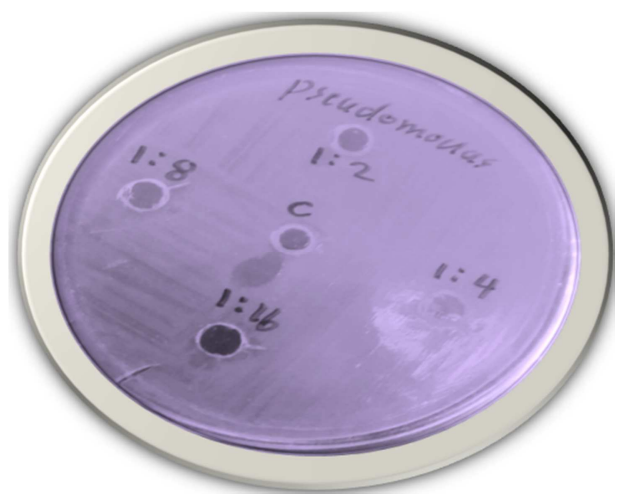

Figure 5. Effect of coriander oil on Pseudomonas aeruginosa ATCC 27853.

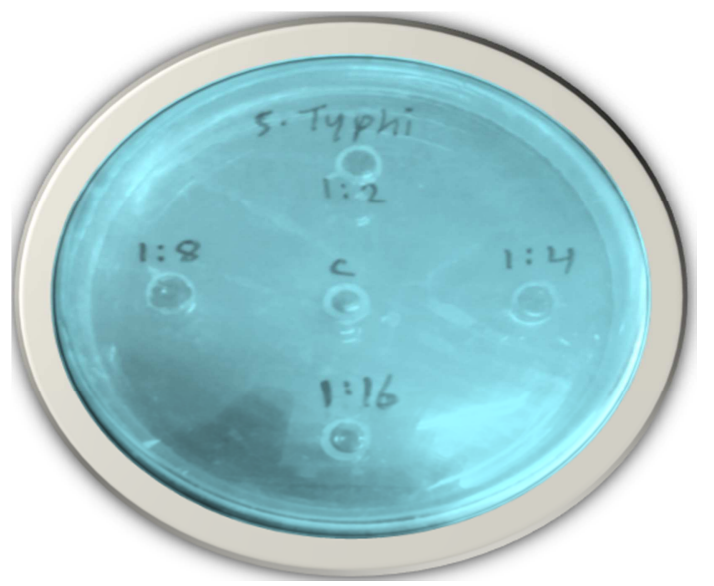

Figure 6. Effect of coriander oil on Salmonella typhimurium ATCC 13311

Table 1. Mean inhibition zones diameter MIZD in mm of coriander oil against six bacteria types with positive control Gentamicin.

\begin{tabular}{|c|c|c|c|c|c|c|}
\hline \multirow[b]{2}{*}{ Tested Bacteria } & \multirow{2}{*}{ Type of bacteria } & \multicolumn{4}{|c|}{ MIZD in $\mathbf{m m}$} & \multirow[b]{2}{*}{ Gentamicin } \\
\hline & & $12.5 \%$ & $25 \%$ & $50 \%$ & $100 \%$ & \\
\hline Bacillus cereus & Positive & 18 & 20 & 23 & 27 & 30 \\
\hline Staphylococcus aureus & Positive & 33 & 36 & 39 & 40 & 32 \\
\hline Enterococcus faecalis & Positive & 0 & 14 & 17 & 20 & 25 \\
\hline Escherichia coli & Negative & 15 & 18 & 21 & 23 & 27 \\
\hline Salmonella typhimurium & Negative & 0 & 13 & 18 & 20 & 30 \\
\hline Pseudomonas aeruginosa & Negative & 18 & 19 & 21 & 23 & 35 \\
\hline
\end{tabular}

In general, the was revealed that the coriander oil appeared higher influence on the positive gram strain rather than negative gram strain, this might be due to that the gram positive strains are more sensitive and potential of hydrophobic essential oils to disrupt the bacterial cell membrane and its structure leading to ion leakage. The antibacterial avtivity of coriander oil showed highly activity against Staphylococcus aureus at all used concentration 
$12.5 \%, 25 \%, 50 \%, 100 \%$ with mean of inhibition zone diameter $(33,36,39$, and 40$) \mathrm{mm}$ respectivlly compared with the antibiotic gentamicin. the crud extrated oil of coriander oil showed variable and good results against the used refernce bacterial strains. The results showed that all tested concentrations of coriander oil as antibacterial activity against gram positive and gram negative bacteria; Salmonella typhimurium and Enterococcus fecalis respectively were appeared resistance at the concentrations $12.5 \%$. In addition the concentration $100 \%$ inflicted the highest antibacterial activities. The most susceptible bacteria strains was Staphylococcus aureus with highest inhibition zone values (33mm) at concentration $25 \%$ and $100 \%(40 \mathrm{~mm})$. On the other hand, the tested concentrations $25 \%$ and $50 \%$ of volatile oil showed high inhibition zone againstBacilluscereus and Proteus vulgaris (20mm) and (23mm) compared with tested concentrations. Previous study had shown that coriander oil caused highest inhibitory zones (23mm) against Salmonella sp compared with E. coli and P. aeruginosa (18 and $10 \mathrm{~mm}$ ) respectively [14].

\section{Conclusion}

An anti microbial is a substance that kills or inhibits the growth of microorganisms such as bacteria and fungi. Three gram-positive were (Bacillus cereus, Staphylococcus aureus and Enterococcus faecalis) and three gram-negative reference strains were (Escherichia coli, Salmonella typhimurium and Pseudomonas aeruginosa). The cup-plate agar diffusion method was used at four different concentrations $(12.5 \%, 25 \%, 50 \%$ and $100 \%)$ and the commercial antibiotic, gentamicin $(10 \mu \mathrm{g})$ was used as standard. The obtained results were calculated as MIZD, so the study found that coriander extract has positive effect on six bacterial spices of especially gram-positive strain and clear impact was showed on Staphylococcus aureus, so that coriander extract can be used pharmaceutically as antibacterial products.

\section{References}

[1] Pino J. A., Rosado, A. and Fuentes V. (1996). Chemical composition of the seed oil of Coriandrum sativum L. from Cuba. J. Essent. Oil. Res., 8: 97-98.
[2] Ravi R. M. and Prakash K. K. (2007). Bhat aroma characterization of coriander (Coriandrum sativum L.) oil samples. Eur. Food Res. Technol, 225 pp. 367-374.

[3] Raal A., Arak E. and Orav A. (2004). Chemical composition of coriander seed essential oil and their conformity with EP standards Agraarteadus, 15: 234-239.

[4] Coskuner Y. and Karababa E. (2007). Physical properties of coriander seeds (Coriandrum sativum L.) J. Food Eng., 80, pp. 408-416.

[5] Mahendra P. and Bisht S. (2011). Coriandrum sativum: a daily use spice with great medicinal effect Pharmacogn J, 3: 84-88.

[6] Keskin S. and Toroglu S. (2011). Studies on antimicrobial activities of solvent extracts of different spices J Environ Biol, 32, pp. 251-256.

[7] Shahwar M. K., El- Ghorab A. H., Anjum F. M., Butt M. S. Hussain S. and Nadeem M. (2012). Characterization of coriander (Coriandrum sativum L.) seeds and leaves: volatile and non volatile extracts. Int J Food Prop, 15, pp. 736-747.

[8] Shibamoto K., Mochizuki M. and Kusuhara, M. (2010). Aroma Therapy in Anti-AgingMedicine. Anti-Aging Medicine, Vol. 7, pp. 55-59.

[9] Porto C., Decorti D. and Kikic I. (2009). Flavour compounds of Lavandula angustifolia L. to use in food manufacturing: Comparison of three different extraction methods. Food Chemistry, Vol. 112, pp. 1072-1078.

[10] Ates D. A. and Erdogrul O. T. (2003). Antimicrobial activities of various medicinal and commercial plant extracts Turk J Biol, 27, pp. 157-162.

[11] Pasqua R., Betts G., Hoskins N., Edwards M., Ercolini D. and Mauriello G. (2007). Membrane toxicity of antimicrobial compounds from essential oils. J. Agric. Food Chem., Vol. 55, pp. $4863-4870$.

[12] Darughe F. Barzegar M. and Sahari M. A. (2012). Antioxidant and antifungal activity of coriander (Coriandrum sativum L.) essential oil in cake Int Food Res; J, 19: 1253-1260.

[13] Teshale C. Hussien J. and Jemal A. (2013). Antimicrobial activity of the extracts of selected Ethiopian aromatic medicinal plants. Spatula DD, 3: 175-180.

[14] Wangesteen H., Samuelsen A. B. and Malterud K. E. (2004). Food Chem., 88: 293. 